\section{Sistemas de classificação de severidade em experimentação animal sob a ótica abolicionista}

Fernandes, Higor Esturião

Escola de Ciências da Vida, Programa de Pós-Graduação em Bioética da Pontifícia Universidade Católica do Paraná, Curitiba,PR, Brasil.E-mail: higorsturiao@gmail.com

\section{Paixão, Rita Leal}

Instituto Biomédico, Universidade Federal Fluminense, Niterói, RJ, Brasil

\section{Fischer, Marta Luciane}

Escola de Ciências da Vida, Programa de Pós-Graduação em Bioética da Pontifícia Universidade Católica do Paraná, Curitiba, PR, Brasil

PALAVRAS CHAVE: experimentação animal, ética animal, abolicionismo

$\mathrm{O}$ princípio dos 3Rs (reduce, refinement e replacement), elaborado por Russell e Burch em 1959, tinha o objetivo de tornar a experimentação científica com animais mais ética e humana. Visava reduzir o número de animais utilizados o máximo possível, aprimorar as técnicas utilizadas e minorar a dor experienciada através de analgésicos e anestésicos, e enfim, quando possível, substituir o uso de animais por métodos alternativos. A influência do princípio foi forte, sendo inclusive incorporado em diretrizes e leis que regulamentam a atividade de pesquisa, inclusive no Brasil, a partir da Lei 11794, a Lei Arouca, de 2008. E pode-se afirmar que a criação dos sistemas de classificação de severidade em experimentação animal, foi uma das consequências da influência emergente dos 3 Rs. O primeiro sistema de classificação de severidade foi proposto em 1979, por David Smyth, que tinha como tarefa categorizar a dor ou sofrimento dos animais, conforme a severidade ou invasividade do experimento, em ordem crescente. Segundo Orlans, os sistemas atuam em quatro frentes: 1) fornecer auxílio as comissões de ética na revisão de protocolos de pesquisa; 2) promover a educação sobre os $3 R$ s para pesquisadores, alunos, técnicos ou qualquer outro profissional que lide com animais; 3) divulgar o número de animais usados em cada categoria do sistema de classificação; e 4) implementar políticas públicas relacionadas ao bem-estar de animais no âmbito da pesquisa e ensino. Aprimoramentos foram feitos do sistema pioneiro de 1978 aos sistemas modernos (que variam, conforme o país), contudo, muitos questionamentos ainda podem ser levantados, não somente em direção as possíveis falhas de ordem mais técnica, mas também à localização moral dos animais. Ora, a ação dos sistemas de classificação se restringe no bem-estar do animal, isto é, foca quase que unicamente na magnitude do sofrimento ocasionado pelo uso destes animais, não no uso em si. É problematizado os efeitos negativos sobre a saúde do animal, mas não é questionado se é ético ou não a utilização de animais como modelos em pesquisa. Nesse sentido, a partir de uma perspectiva abolicionista, o presente trabalho analisou, através de levantamento bibliográfico, os limites destes sistemas, os conflitos morais presentes e os problemas decorrentes da concepção do animal como propriedade. Concluiu-se que os sistemas de classificação, por não questionarem o status de propriedade do animal, por não interrogarem sua condição de escravidão especista, podem estar reproduzindo ou mascarando uma lógica de dominação, em que o animal ainda é utilizado como objeto, como tubo de ensaio. Para a mudança deste cenário, sob a ótica do abolicionismo, faz se necessário a criação de uma ética que trata o animal não como propriedade, mas sim como sujeito de direito.

\section{REFERÊNCIAS}

[1] FENWICK, N.; ORMANDY, E.; GAUTHIER, C.; GRIFFIN, G. Classifying the severity of scientific animal use: a review of international systems. Animal Welfare, v.20, n.2, p. 281-301, 2011.

[2] FRANCIONE, G. L. Introdução aos direitos animais: seu filho ou o cachorro. Campinas: Editora Unicamp, 2015.

[3] ORLANS, F. B. Animal pain scales in public policy. Alternatives to Laboratory Animals, v.18, p.41-50, 1990.

[4] RUSSEL, W. M. S.; R.L. BURCH, R. L. The principles of humane experimental technique. London: Methuen \& Co Ltd, 1992 